\title{
Temperature Sensing in Cells Using Polymeric Upconversion Nanocapsules
}

\author{
Banu Iyisan, Raweewan Thiramanas, Nadzeya Nazarova, Yuri Avlasevich, Volker Mailänder, \\ Stanislav Baluschev, and Katharina Landfester*
}

Cite This: Biomacromolecules 2020, 21, 4469-4478

Read Online

\section{ACCESS |}

Џlll Metrics \& More

Article Recommendations

Supporting Information

ABSTRACT: Monitoring local temperature inside cells is crucial when interpreting biological activities as enhanced cellular metabolism leads to higher heat production and is commonly correlated with the presence of diseases such as cancer. In this study, we report on polymeric upconversion nanocapsules for potential use as local nanothermometers in cells by exploiting the temperature dependence of the triplet-triplet annihilation upconversion phenomenon. Nanocapsules synthesized by the miniemulsion solvent evaporation technique are composed of a polymer shell and a liquid core of rice bran oil, hosting triplet-triplet annihilation upconversion active dyes as sensitizer and emitter molecules. The sensitivity of the triplet-triplet annihilation upconversion to the local oxygen concentration was overcome by the oxygen reduction ability of the rice bran oil core. The triplet-triplet annihilation upconversion process could thus successfully be applied at different levels of oxygen presence including at ambient conditions. Using this method, the local temperature within a range of 22 to $40{ }^{\circ} \mathrm{C}$ could be determined when

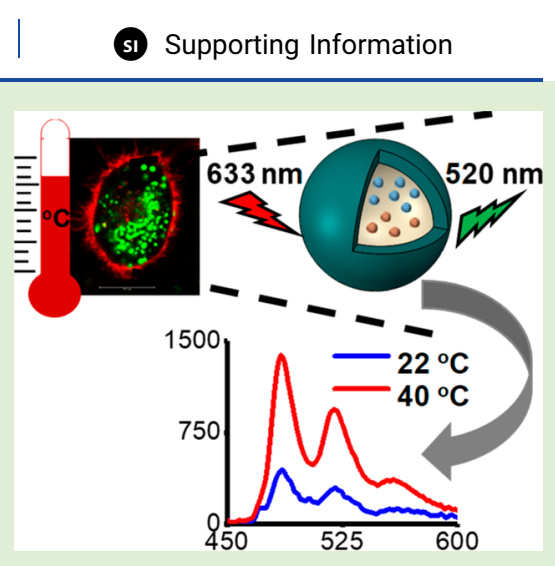
the upconversion nanocapsules were taken up by HeLa cells with good cellular viability. Thus, the higher cell temperatures where the cells show enhanced metabolic activity led to a significant increase in the delayed fluorescence spectrum of the upconversion nanocapsules. These findings are promising for further development of novel treatment and diagnostic tools in medicine.

\section{INTRODUCTION}

Gathering information on local temperature in cells promotes understanding their biological activities. It is well-known that cellular activities like enzyme reactions and cell division correlate strongly with temperature changes. ${ }^{1-3}$ For instance, due to their increased metabolism, continuously growing malignant cells produce more heat in comparison to healthy ones. ${ }^{4,5}$ Given this, determining the local temperature within a cell makes it possible for us to develop novel treatments and diagnostic tools in medicine. Nevertheless, there are significant technological challenges that initially need to be overcome. First, the temperature probe should be small in comparison to the cell compartments, that is, it must be of nanoscale size to enable local heat monitoring, but not able to influence the real cell temperature. Second, the required small size of the temperature probe should permit good cellular uptake to allow enough of them inside the cells. Third, the temperature probe needs to be entirely biocompatible and it should not interfere with cell-metabolism processes during temperature recording.

Polymeric nanocapsules ${ }^{6-8}$ offer a solution to gaining the necessary above-mentioned functions because of the ease of their flexible structural design for an optimized shell/core balance and sufficient cellular uptake. Additionally, nanocapsules can be constructed in such a way as to be temperature-responsive by adding the corresponding sensitive units either to the polymer shell ${ }^{9}$ or to the core through the right cargo combinations. Given this, a minimally invasive strategy for providing a temperature-sensing response to the nanocapsules is to use luminescent-based tools that are sensitive to temperature alterations ${ }^{10-12}$ for further use as intracellular thermometers. ${ }^{13,14}$

Using excitation light with wavelengths shifted to the biologically less-interactive optical region of deep-red or NIR-A is a harmless approach, as such light penetrates the tissue deep enough without causing significant side effects. ${ }^{15,16}$ The crucial benefit of using deep-red light is that the excitation light will not cause undesired autofluorescence of the cell culture or nutrient mixtures. A promising tool to do this is to use photon energy upconverting processes that can generate higher-energy photons via excitation of lower energy photons. ${ }^{17}$ Various nonlinear optical processes, such as twophoton absorption, ${ }^{18}$ second harmonic generation, ${ }^{19}$ rare earth ion (e.g., lanthanide, $\mathrm{Ln}^{3+}$ ) based upconversion (excited state absorption or energy transfer), ${ }^{20}$ and triplet-triplet annihilation upconversion (TTA-UC), ${ }^{21-23}$ exist for realizing

Special Issue: Polymer Colloids: From Fundamentals to Application

Received: March 12, 2020

Revised: May 20, 2020

Published: May 20, 2020

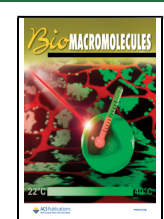


upconversion (UC) processes. Among them, TTA-UC is the only upconversion process performed using photons from a noncoherent optical source with very low excitation intensity (on the level of $20 \mathrm{~mW} \mathrm{~cm}^{-2}$ ). Additionally, the excitation and emission spectrum of the TTA-UC-based system can be tuned freely by using a suitable combination of sensitizer and emitter couples from a large molecular library. ${ }^{17,21}$

The vast majority of the TTA-UC systems reported in the literature are hydrophobic; therefore, the transfer of the annihilation upconversion process into a water environment is a necessary requirement for applications in the life sciences. This has been partially achieved by incorporating UC dyes into dendrimers, ${ }^{24}$ micelles, ${ }^{25}$ polymers, ${ }^{26-29}$ silica, ${ }^{30}$ or proteinbased nanoparticles. ${ }^{31}$ However, since oxygen molecules penetrate nanosized objects (even if the penetration rate is slowed down), oxygen quenching in the process of TTA-UC optically excited triplet states still takes place. ${ }^{32}$ Given this, core/shell structured nanoparticles (i.e., nanocapsules) are a viable option as their hydrophobic core can be loaded with oxygen-scavenging substances. In the presence of molecular oxygen, the TTA-UC process is unavoidably linked to the generation of singlet oxygen, known as a very aggressive species. If the rate of oxygen "consumption", that is, the rate of covalent bonding of the singlet oxygen with the singlet oxygen scavenging moiety, is higher than the rate of oxygen penetration through the NC shell, it is possible to mimic "oxygen-free conditions". So far, some examples of TTA-UC processing in the presence of oxygen have been shown, ${ }^{31,33-37}$ and it is possible to develop this processing for use in medical applications such as the construction of nanothermometers. ${ }^{38}$

To date, most reported luminescent nanothermometers have been developed with lanthanide-based upconversion nanoparticles (UCNPs). ${ }^{39-41}$ In contrast, TTA-UC based nanocapsules have been mainly fabricated for bioimaging applications ${ }^{28-31,42}$ and for the construction of solar cell devices. ${ }^{37,43}$ However, the intensified development of polymeric nanocapsules and their good biosafety profile can be combined with the advantages of the TTA-UC process for further advancement in this field. In this work, we demonstrate the synthesis of polymeric upconversion nanocapsules and go on to use them for a temperature-dependent in vitro TTA-UC process in cells exposed to the ambient environment to study their applicability as nanothermometers. The shell of the nanocapsules was selected to be biologically compatible poly(methyl methacrylate) (PMMA) ${ }^{44}$ and the NC core was rice bran oil ( $\mathrm{RBO}$ ), which serves as an efficient singlet oxygen quencher. Scheme 1 illustrates the general approach toward in vitro temperature-sensing in HeLa cells via TTA-UC, together with the chemical structures of the encapsulated sensitizer and emitter couple.

\section{EXPERIMENTAL SECTION}

Materials. Poly(methyl methacrylate) (PMMA, $120 \mathrm{kDa}$ ) and sodium dodecyl sulfate (SDS, 99\%) were purchased from SigmaAldrich. Chloroform and dimethyl sulfoxide (DMSO, 99.7\%, extra dry) were obtained from Acros Organics. A dialysis membrane made of regenerated cellulose (molecular weight cutoff $6-8 \mathrm{kDa}$ ) was purchased from Carl Roth. Pd-meso-tetraphenyl tetrabenzoporphyrin $(\mathrm{PdTBP})^{45,46}$ and 3,10-bis(3,3-dimethylbutyl-1-yn-1-yl)perylene $(\mathrm{BDMBP})^{37}$ were synthesized as reported previously. Sterile $\mathrm{H}_{2} \mathrm{O}$ was obtained from Braun Melsungen AG.

Nanocapsule Formation. The nanocapsules were synthesized using the miniemulsion solvent evaporation technique. The dispersed phase contained the solution of PMMA $(150 \mathrm{mg})$, PdTBP $(3.3 \times$
Scheme 1. Polymeric Upconversion Nanocapsules Sensing Temperature in HeLa Cells (top) and Structures of the Sensitizer, meso-Tetraphenyl-tetrabenzo[2,3] porphyrin Palladium(II) (PdTBP, bottom left), and Emitter, 3,10Bis(3,3-dimethylbut-1-ynyl)perylene (BDMBP, bottom right)

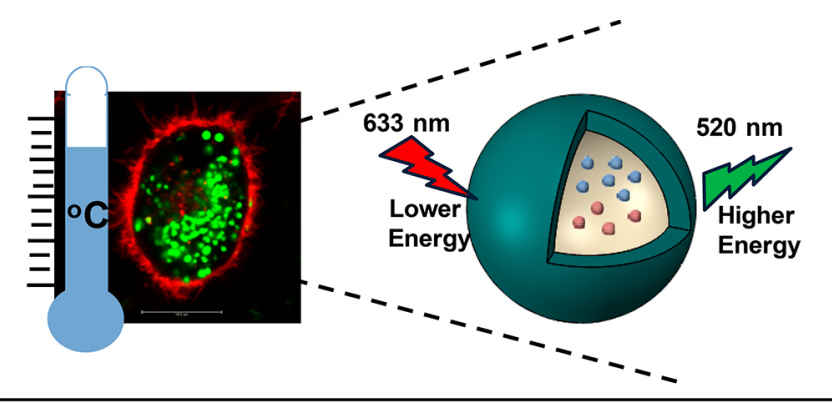

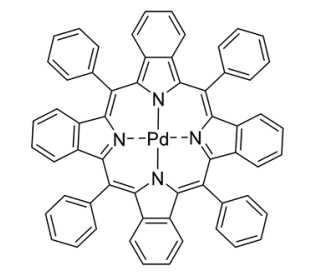

- PdTBP sensitizer
Encapsulated upconversion dyes

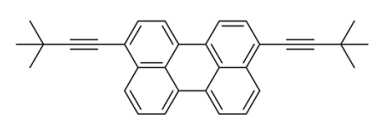

- BDMBP emitter
$10^{-8} \mathrm{~mol}$ for UCNC1 and $3.3 \times 10^{-7} \mathrm{~mol}$ for UCNC2), BDMBP $(3.3$ $\times 10^{-7} \mathrm{~mol}$ for UCNC1 and $3.3 \times 10^{-6} \mathrm{~mol}$ for UCNC2), rice bran oil $(300 \mathrm{mg})$, and chloroform $(1.8 \mathrm{~mL})$, whereas the surfactant (SDS, $10 \mathrm{mg}$ ) was dissolved in sterile $\mathrm{H}_{2} \mathrm{O}(10 \mathrm{~mL})$ forming the continuous phase. Afterward, these two phases were mixed and pre-emulsified by stirring at $1000 \mathrm{rpm}$ for an hour, followed by ultrasonication for $2 \mathrm{~min}$ with a Branson Sonifier W450 at $90 \%$ amplitude (10 s pulse/10 s pause) under ice cooling. Lastly, chloroform was slowly removed at 30 ${ }^{\circ} \mathrm{C}$ by stirring the dispersion at $300 \mathrm{rpm}$ for $16 \mathrm{~h}$. The nanocapsule dispersions were filtered and dialyzed against distilled water using a membrane with a molecular cutoff (MWCO) 6-8 kDa for $16 \mathrm{~h}$ before the cellular uptake and UC measurements.

Nanocapsule Characterization. Dynamic light scattering (DLS) measurements were performed at $25^{\circ} \mathrm{C}$ using a Zetasizer Nanoseries instrument (Malvern Instruments, UK) equipped with a $633 \mathrm{~nm} \mathrm{He}-$ Ne laser at a fixed scattering angle of $90^{\circ}$ to determine the size of the nanocapsules as intensity-average diameter $\left(z_{\text {average }}\right)$ values. The nanocapsules were diluted 100 times for the DLS measurements. The zeta $(\zeta)$ potential of the nanocapsules $(15 \mu \mathrm{L})$ was determined by electrophoretic light scattering using a Zetasizer Nano Z instrument (Malvern Instruments, UK) in $1 \mathrm{mM}$ potassium chloride solution (1 $\mathrm{mL}$ ) at $25{ }^{\circ} \mathrm{C}$. The morphology of the nanocapsules was investigated by using JEOL 1400 (Jeol Ltd., Tokyo, Japan) for transmission electron microscopy (TEM) operating at an acceleration voltage of $120 \mathrm{kV}$. Samples were prepared by dropping the diluted nanocapsule dispersions $\left(1.6 \mathrm{mg} \cdot \mathrm{mL}^{-1}\right)$ onto 300 -mesh carbon-coated copper grids followed by removal of excess water using a piece of filter paper to decrease artifacts caused by drying.

Determination of the Dye Amounts. The dialyzed nanocapsules were freeze-dried for $24 \mathrm{~h}$ and dissolved at two different concentrations in DMSO $\left(4.1 \mathrm{mg} \cdot \mathrm{mL}^{-1}, 8.2 \mathrm{mg} \cdot \mathrm{mL}^{-1}\right.$, Figure $\mathrm{S} 1$ in SI). In order to obtain the calibration curves (see Figures S2 and S3 in $\mathrm{SI}$ ), the solutions of PdTBP and BDMBP dyes were also prepared in DMSO. Afterward, the absorbance $(380-800 \mathrm{~nm})$ of the samples was measured using a Tecan infinite plate reader in duplicate. From this data, the absorbance values at 479 and $630 \mathrm{~nm}$ were used to estimate the concentration of encapsulated PdTBP and BDMBP dyes, respectively. By this method, the dye encapsulation efficiency after dialysis was calculated as an average value.

Upconversion Measurements. A homemade setup was used to obtain the luminescence spectra of the nanocapsules. For the samples 
(a)

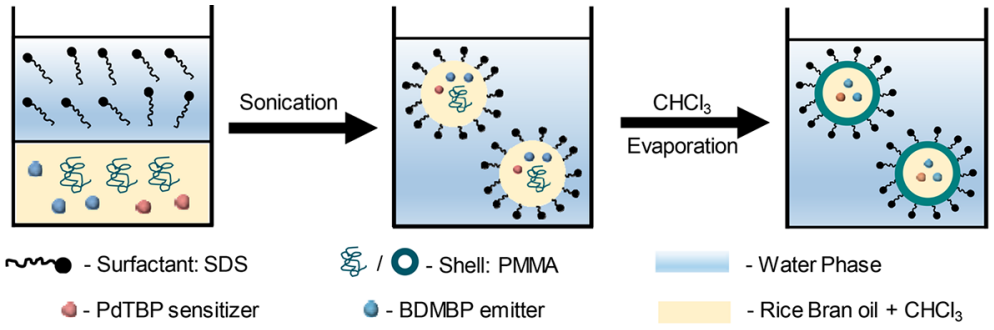

\begin{tabular}{|c|c|c|c|c|c|c|c|c|c|}
\hline \multirow[t]{2}{*}{ Nanocapsule } & \multirow[t]{2}{*}{$\begin{array}{l}\text { Diameter } \\
(\mathrm{nm}) / \text { PDI }\end{array}$} & \multirow{2}{*}{$\begin{array}{c}\text { Zeta } \\
\text { Potential } \\
(\mathrm{mV})\end{array}$} & \multirow{2}{*}{$\begin{array}{c}\text { Solid } \\
\text { Content } \\
(w t \%)\end{array}$} & \multicolumn{2}{|c|}{$\begin{array}{c}\text { PdTBP } \\
\text { Sensitizer [M] }\end{array}$} & \multicolumn{2}{|c|}{$\begin{array}{c}\text { BDMBP } \\
\text { Emitter [M] }\end{array}$} & \multicolumn{2}{|c|}{$\begin{array}{l}\text { Encapsulation } \\
\text { Efficiency (\%) }\end{array}$} \\
\hline & & & & initial $^{*}$ & purified & initial* $^{*}$ & purified & PdTBP & BDMBP \\
\hline UCNC1 & $220 / 0.10$ & -51.7 & 4.1 & $3.3 \times 10^{-6}$ & $1.87 \times 10^{-6}$ & $3.3 \times 10^{-5}$ & $2.62 \times 10^{-5}$ & 56.7 & 79.4 \\
\hline UCNC2 & $224 / 0.09$ & -52.2 & 4.1 & $3.3 \times 10^{-5}$ & $1.88 \times 10^{-5}$ & $3.3 \times 10^{-4}$ & $2.55 \times 10^{-4}$ & 57.0 & 77.3 \\
\hline
\end{tabular}

${ }^{*}$ Added amount of the dyes during in-situ encapsulation before the purification through filtering and dialysis steps. The dye concentrations are given in whole dispersion volume.

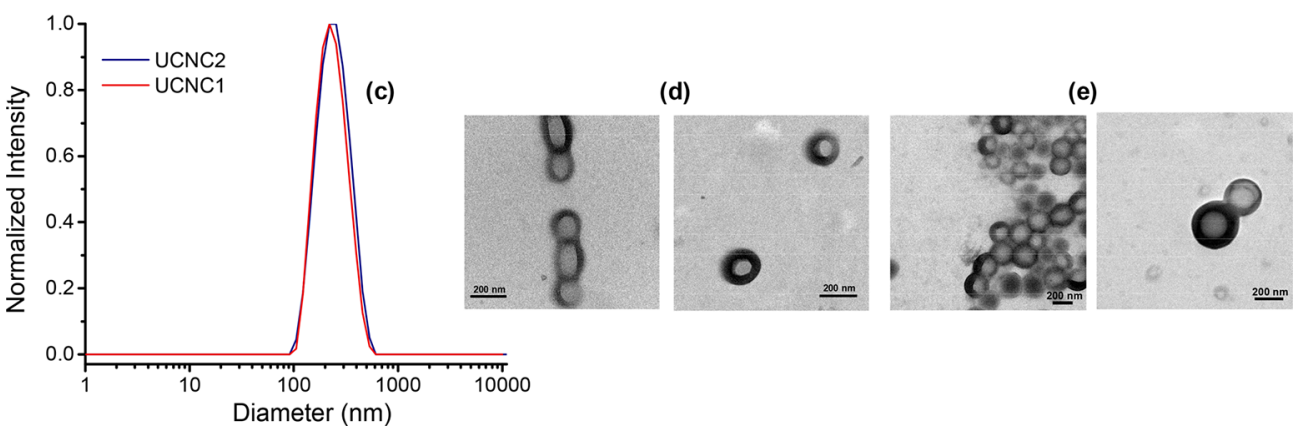

Figure 1. (a) Synthetic scheme of polymeric upconversion nanocapsules (UCNCs) through miniemulsion/solvent evaporation. (b) Physicochemical characteristics and encapsulation efficiencies of UCNCs after purification steps. (c) Size distribution of the UCNCs obtained from dynamic light scattering measurements. TEM micrographs of (d) UCNC1 and (e) UCNC2, showing the core/shell structure of the capsules.

measured in an ambient environment, the dispersions were filled into a cuvette ( $1 \mathrm{~mm}$ thickness) without any further deoxygenation step and immediately after the dialyzed nanocapsules were ready. For the samples measured at a lower oxygen level, the dispersions were placed into the glovebox (oxygen amount $\sim 4 \mathrm{ppm}$, UNIlab glovebox, M. braun $\mathrm{GmbH}$ ) and stirred overnight, then filled into the cuvettes and sealed using a parafilm to keep the oxygen level constant. For the temperature dependent measurements, the sample (cuvette or cells) was located in a holder in which the temperature was controlled using a Peltier element by means of the T-app computer program from Electron Dynamics Ltd. (Southampton, UK). The sample temperature was additionally measured using a thermistor (PT100) attached on top of the sample (cuvette or cells). The light excitation was performed by a HeNe laser at the wavelength of $\lambda_{\text {exc }}=633 \mathrm{~nm}$. The excitation intensity for the nanocapsules at their highest concentration $\left(41 \mathrm{mg} \cdot \mathrm{mL}^{-1}\right)$ was set up as $16 \mathrm{~mW} \cdot \mathrm{cm}^{-2}$, whereas the diluted dispersion inside the HeLa cells was excited at varied excitation intensities from $32 \mathrm{~mW} \cdot \mathrm{cm}^{-2}$ to $256 \mathrm{~mW} \cdot \mathrm{cm}^{-2}$. The excitation power was controlled by a power meter PM100D (Thorlabs, USA), and the laser spot diameter was $0.002 \mathrm{~m}$.

For the in vitro TTA-UC measurements, the samples were prepared as follows. HeLa cells were seeded at a density of $6 \times 10^{4}$ cells in a 35 $\mathrm{mm}$ Petri dish with a glass coverslip bottom ( $\mu$-Dish, $7 \mathrm{~mm}$ walls, Ibidi, Germany) and cultured for $24 \mathrm{~h}$ in DMEM complete medium. The cells were then incubated for $24 \mathrm{~h}$ with the nanocapsules at $6 \mathrm{mg}$. $\mathrm{mL}^{-1}$ (UCNC1, UCNC2). Then, the cells were washed five times with $500 \mu \mathrm{L}$ of DMEM to remove the remaining nanocapsules outside the cells and finally suspended in $1 \mathrm{~mL}$ DMEM. Subsequently, the HeLa cells incubated with UCNCs were placed into a temperature-controlled sample holder, and the variation of the temperature, ranging from 22 to $40{ }^{\circ} \mathrm{C}$, was controlled as explained above.
Cell Culture. HeLa cells obtained from DSMZ (Deutsche Sammlung von Mikroorganismen and Zellkulturen, Germany) were cultured in Dulbecco's Modified Eagle's Medium (DMEM, Gibco, USA) containing $10 \%$ fetal bovine serum (FBS, Gibco, USA), 1\% Lglutamine (Gibco, USA), and $1 \%$ penicillin/streptomycin (Gibco, USA). They were incubated at $37{ }^{\circ} \mathrm{C}$ in a $\mathrm{CO}_{2}$ incubator with $95 \%$ humidity and $5 \% \mathrm{CO}_{2}$ (C200, Labotect, Germany). To dissociate adherent cells, the cells were trypsinized with $0.25 \%$ trypsin (Gibco, USA) for $3 \mathrm{~min}$ as a general procedure. The cell pellet was collected by centrifugation at $130 \mathrm{~g}$ for $3 \mathrm{~min}$, resuspended in DMEM complete medium, and used for further assays. Viable cells were determined by the trypan blue exclusion method and counted by using TC10 automated cell counter (Bio-Rad, USA).

Cell Viability. To study cytotoxicity testing of UCNCs, HeLa cells resuspended in DMEM complete medium were seeded at a density of 6400 cells per well in a 96-well plate for $24 \mathrm{~h}$. The cells were then treated with various concentrations of the corresponding nanocapsules from 500 to $10000 \mu \mathrm{g} \cdot \mathrm{mL}^{-1}$ for $24 \mathrm{~h}$. An untreated sample was used as a negative control and calculated as $100 \%$ cell viability, while a $20 \%$ DMSO-treated sample was used as a positive control. After that, cell viability was evaluated by using the CellTiter-Glo luminescent cell viability assay (Promega, USA) according to the manufacturer's protocol. This assay is based on the amount of ATP present, which reflects the presence of metabolically active cells. Luminescence was recorded $10 \mathrm{~min}$ after reagent addition using a plate reader (Infinite M1000, Tecan, Germany). The $\mathrm{EC}_{50}$ values were calculated by fitting a curve with nonlinear regression using GraphPad Program.

Cellular Uptake Study by Flow Cytometry. For the cellular uptake study, HeLa cells resuspended in DMEM complete medium were seeded at a density of $8 \times 10^{4}$ cells per well in a 24 -well plate for $24 \mathrm{~h}$. After removal of the old medium, the cells were treated with various concentrations of UCNCs from 1000 to $8000 \mu \mathrm{g} \cdot \mathrm{mL}^{-1}$ for 24 


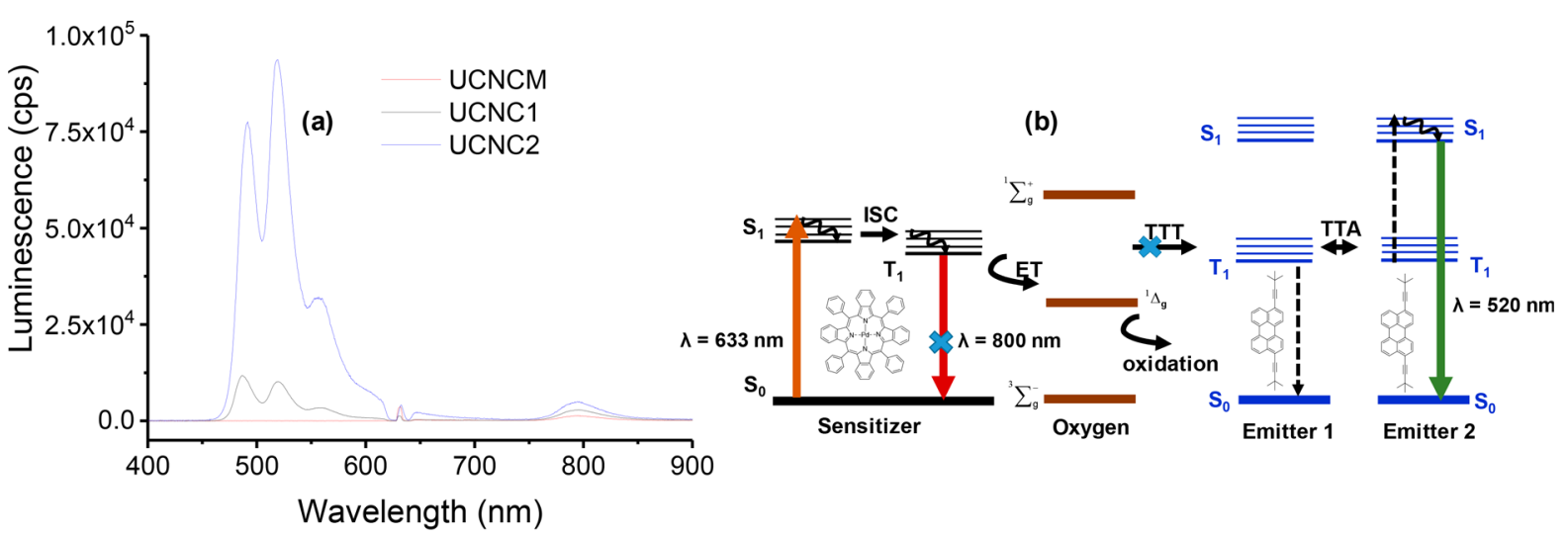

(c)

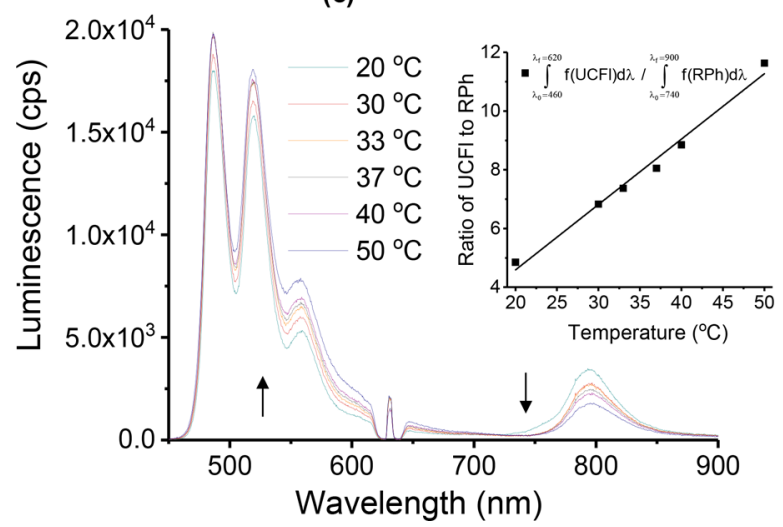

(d)

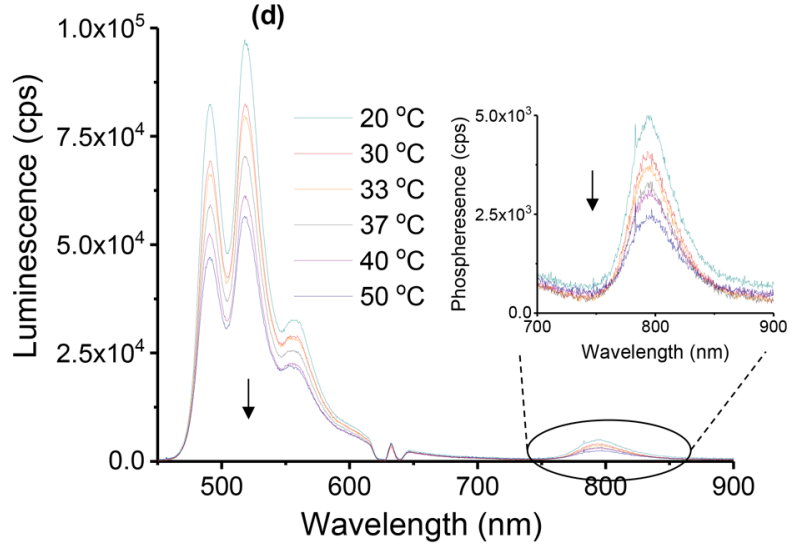

Figure 2. (a) Luminescent spectra of UCNCs at ambient conditions $\left(21 \% \mathrm{O}_{2}\right)$ without applying any deoxygenation steps. (b) Energy diagram of triplet-triplet annihilation upconversion in the UCNCs in the presence of oxygen. (c) Temperature-dependent luminescence spectra of (c) $\mathrm{UCNC} 1$ and (d) UCNC2 at low-level oxygen presence $(\sim 4 \mathrm{ppm})$. For all figures, excitation at $\lambda_{\text {exc }}=633 \mathrm{~nm}$ and excitation intensity $\sim 16 \mathrm{~mW}$. $\mathrm{cm}^{-2}$.

h. Thereafter, the cells were collected from the plate by detaching them with trypsin and stained with Zombie Aqua Fixable Viability Kit (BioLegend, USA) according to the manufacturer's instructions for live cell gating. Flow cytometry measurements were performed on an Attune NxT Flow Cytometer (Invitrogen, USA). Zombie Aqua dye was excited with the violet laser $(405 \mathrm{~nm})$ and has a maximum emission of $516 \mathrm{~nm}$, which can be detected in channel VL-2. The fluorescence-positive cells represented the cells that took up the UCNCs containing BDMBP dye and were recorded in channel BL-1 with the excitation of blue laser $(488 \mathrm{~nm})$. Data analysis was performed using Attune NxT software (Invitrogen, USA) by selecting the cells on a forward/sideward scatter plot, thereby excluding cell debris. These gated events were shown in the histogram of fluorescent signals. After gating the living cells, percentages of BDMBP-positive cells and their median fluorescence intensities were reported.

Cell Imaging by Confocal Laser Scanning Microscopy (cLSM). For confirmation of cellular uptake, the progress of HeLa cells' uptake of UCNCs was followed at different times by imaging with confocal laser scanning microscopy (cLSM). HeLa cells were seeded at a density of $2 \times 10^{4}$ cells per well in $\mu$-Slide 8 well with a glass coverslip bottom (Ibidi, Germany) and cultured for $24 \mathrm{~h}$ in DMEM complete medium (phenol red free). After removing the old medium, the cells were incubated for $1,8,24$, and $48 \mathrm{~h}$ with UCNCs resuspended in DMEM at a concentration of $6000 \mu \mathrm{g} \cdot \mathrm{mL}^{-1}$. Subsequently, the cells were washed five times with $200 \mu \mathrm{L}$ of DMEM to remove the remaining nanoparticles outside the cells, the subcellular organs were stained with fluorescent dyes, and finally the cells were suspended in DMEM. Live cell images were taken with a commercial setup (LSM SP5 STED Leica Laser Scanning Confocal Microscope, Leica, Germany), consisting of an inverse fluorescence microscope DMI 6000 CS equipped with a multilaser combination and five detectors operating in the range of $400-800 \mathrm{~nm}$. A HCX PL APO CS $63 \times 1.4$ oil objective was used in this study. The excitation and detection conditions in a sequential mode were described as follows: Fluorescent nanoparticles containing BDMBP dye were excited with an Ar laser (488 nm), detected at 510-540 nm, and pseudocolored in green. The cell membrane was stained with CellMaskOrange $\left(5 \mu \mathrm{g} \cdot \mathrm{mL}^{-1}\right.$, Life technologies, USA), excited with a DPSS laser $(561 \mathrm{~nm})$, and detected at $570-600 \mathrm{~nm}$, pseudocolored in red.

\section{RESULTS AND DISCUSSION}

Formation and Characterization of Upconversion Nanocapsules. Nanocapsules were formed by applying the miniemulsion solvent evaporation method, as illustrated in Figure 1a. In brief, two immiscible phases were emulsified to form surfactant stabilized oil droplets including the upconversion dyes and the dissolved poly(methyl methacrylate) (PMMA) in its effective solvent. The continuous phase was water. The shell formation took place through polymer precipitation at the rice bran oil $(\mathrm{RBO}) /$ water interface after the chloroform, an effective solvent for PMMA, completely evaporated. As mentioned, RBO was used as the liquid core to host the PdTBP (sensitizer) and BDMBP (emitter) (Scheme 1) molecules to conduct further TTA-UC processes. The $\pi$ extended perylene emitter BDMBP was chosen since it shows a three times higher quantum yield of upconversion with PdTBP as compared to the parent perylene chromophore. Rice bran oil was selected primarily because this natural product is FDAapproved and its main components are unsaturated fatty acids 
such as linoleic acid $(35.6 \%)$ and oleic acid $(40.6 \%)^{47}$ with a pronounced oxygen scavenging potential. Further, rice bran oil can produce stable peroxides, thus reducing the oxygen concentration inside the nanoconfined object, as observed previously for soy bean oil encapsulated BSA nanocapsules. ${ }^{31}$ In addition, PMMA is known as a biocompatible polymer as applied in various medical applications, including use as a drug carrier, as an adjuvant for vaccines, and in dental materials. ${ }^{44}$ Figure 1 shows the colloidal characteristics of the synthesized nanocapsules, the only difference between UCNC1 and UCNC2 being the amount of the encapsulated dye molecules. The average sizes of the nanocapsules were about $220 \mathrm{~nm}$ (UCNC1) and $224 \mathrm{~nm}$ (UCNC2) with a narrow size distribution range determined by dynamic light scattering measurements (Figure 1b,c). In addition, the electrostatic stabilization of the nanocapsules by the anionic surfactant SDS provided high stability even though it was only used in small amounts as supported by the zeta potential analysis. The UCNCs kept their integrity for several months without any macroscopic phase separation. In addition, the core/shell morphology of the particles was confirmed by TEM investigation, as sufficient contrast between the PMMA shell and the oil core led to a clear identification of the nanocapsule structure, as seen in Figure 1d,e. Since the encapsulated sensitizer and emitter amounts have a significant effect on the resulting luminescent properties of the upconversion nanocapsules, $^{21,48}$ the loading efficiency of the corresponding dyes were determined, as given in Figure $1 \mathrm{~b}$. Here, the initial concentration ratio of the BDMBP emitter to PdTBP sensitizer changed from 10:1 to $14: 1$ for both UCNC1 and UCNC2 nanocapsules. This clearly underlines that the loss of the emitter was less than that of the sensitizer during the emulsification and purification steps. It is most probable that parts of the sensitizer were accumulated in the shell. On the other hand, the difference of the total dye concentrations between the nanocapsules were kept the same (UCNC2 embed nearly 10 times more dyes than the UCNC1), and this was important in order to gain information in the next luminescence experiments.

As a next step, the photoluminescent characteristics of the synthesized nanocapsules were investigated. The first test was to evaluate the upconversion efficiency of the nanocapsules in the case of an oxygen-saturated environment. To do this, an additional nanocapsule (UCNCM, Figure S4 in SI) was prepared with hexadecane (HD) as a liquid core. All specifications except the core material were kept the same to serve as a control function. The size of the control UCNCM was about $230 \mathrm{~nm}$ with a zeta potential of about $-51.4 \mathrm{mV}$ (after dialysis) with the same amount of dye concentration as UCNC1 capsules. Afterward, the triplet-triplet annihilation upconversion process was initiated as reported in the luminescence spectra of the produced UCNC samples in Figure 2. The energy diagram of the TTA-UC is illustrated in Figure $2 \mathrm{~b}$ : briefly, the optical excitation of the nanocapsules with red light $\left(\lambda_{\text {exc }}=633 \mathrm{~nm}\right.$ ) led to photon absorption by the PdTBP sensitizer, present in the core of the UCNCs, and was followed by intersystem crossing (ISC) resulting in efficient generation of the sensitizer triplet states. Next, this energy was transferred to an emitter triplet state via the process of triplettriplet transfer (TTT). Further, the excited triplet states of two emitter molecules showed triplet-triplet annihilation (TTA) that led to the return of one emitter molecule to its singlet state, whereas the other one gained energy and populated the excited singlet state. Thus, the radiative decay of the emitter from its excited singlet state to its ground state provided delayed fluorescence (upconversion fluorescence, UC) with photon energy significantly higher than the energy of the excitation photons. It should also be noted that residual phosphorescence of the sensitizer was also observable, as the sensitizer triplet population was not completely transferred. In the presence of vanishing oxygen concentrations, even on the ppm level, the efficiency of the TTA-UC process was significantly influenced. ${ }^{32,49-51}$ When oxygen was present, the stored energy in the triplet ensembles of the sensitizer was not only transferred to the emitter molecules but was also transferred to the ground state of the molecular oxygen, causing singlet oxygen formation that further oxidized the dye molecules leading to decreased efficiency. This may lead to complete quenching but may also be only a competing reaction for the further steps in this process. Thus, the complexity of the studied process is reflected in the luminescence spectra of the established nanocapsules (Figure 2a). Here, hexadecane bearing nanocapsules (UCNCM) did not show any upconversion fluorescence as the complete sensitizer triplet energy was shared with the oxygen present and the residual phosphorescence (the optical signal with local maxima at nearly $\lambda=800 \mathrm{~nm}$, Figure $2 \mathrm{a}$ ). However, nanocapsules bearing $\mathrm{RBO}$ as a liquid core (UCNC1, UCNC2) showed wellobservable upconversion fluorescence (the optical signal with local maxima at nearly $\lambda=520 \mathrm{~nm}$, Figure $2 \mathrm{a}$ ) in an ambient environment. It must be pointed out that no further deoxygenation was applied to the nanocapsules. Thus, RBO core nanocapsules fulfill the antioxidant requirement in order to have enough UC efficiency when the nanocapsules are taken up in HeLa cells.

We further studied the TTA-UC triggered temperaturedependence of the nanocapsules in the range of 20 to $50{ }^{\circ} \mathrm{C}$ (Figure $2 \mathrm{c}, \mathrm{d}$ ). To do this, the oxygen content of the UCNC was lowered by keeping the nanocapsules in a nitrogen-filled glovebox (oxygen amount $\sim 4 \mathrm{ppm}$ ) overnight, and they were then filled into the cuvettes in the same environment. In the case of the UCNC1 nanocapsules, that is, the NCs bearing the lower concentration of the UC dyes, we observed, as expected, a proportional relationship between temperature and UC fluorescence intensity, whereas the intensity of the residual phosphorescence decreased with an increase in temperature. ${ }^{52}$ This allows creation of an unambiguous temperature calibration curve, if the ratio of the delayed fluorescence signal to the residual phosphorescence signal is used as a materialresponse parameter to the temperature changes. The calibration curve is shown in the inset of Figure 2c. However, surprisingly, a higher concentration of sensitizer and emitter (UCNC2, Figure 2d) within the core led to a decrease of the intensities of both UC fluorescence and residual sensitizer phosphorescence with increasing sample temperature. Such behavior was seen previously in the 9,10-diphenylanthraceneterminated $\operatorname{poly}(\varepsilon \text {-caprolactone nanoparticles })^{27}$ in air-saturated nanogels ${ }^{53}$ and in PEGylated phospholipid liposomes sourced by the change of membrane fluidity depending on the gel to liquid phase transition temperature $\left(T_{\mathrm{m}}\right)^{54}$

Although we conducted the measurements after partial removal of the oxygen, it was not possible to deoxygenate the dispersions completely, even given ideal conditions (nitrogen filled glovebox, oxygen level was $4 \mathrm{ppm}$ ). The synthetic procedure required 2 days before further UC measurements could be carried out. This means that the oxygen has more or 


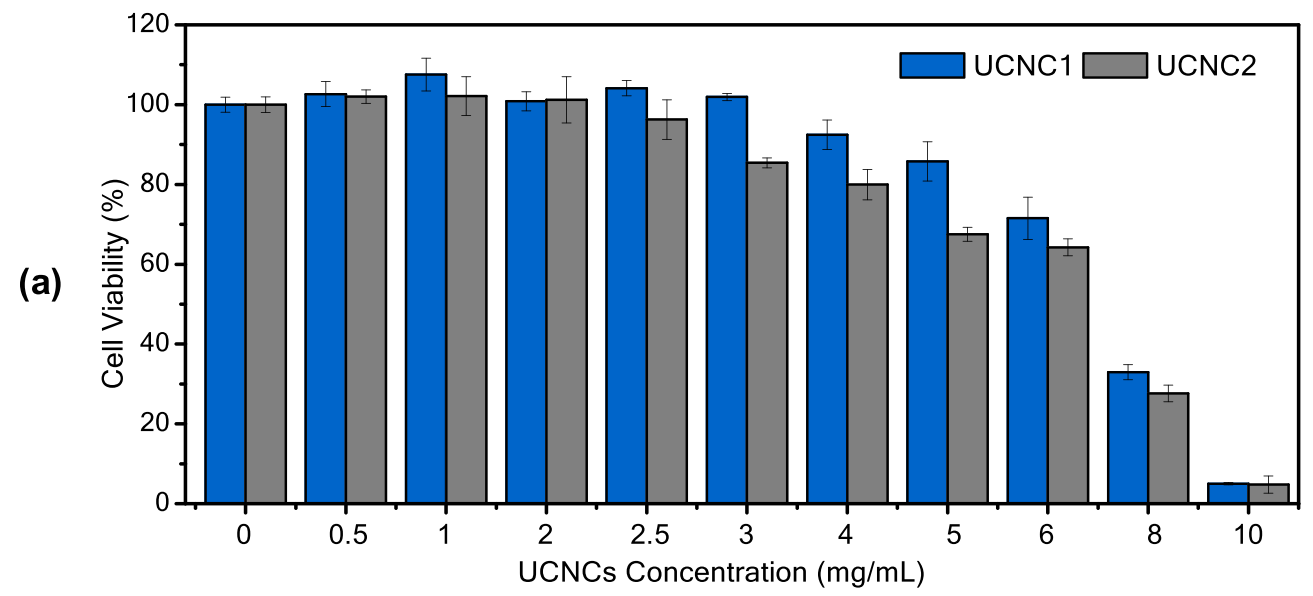

(b)
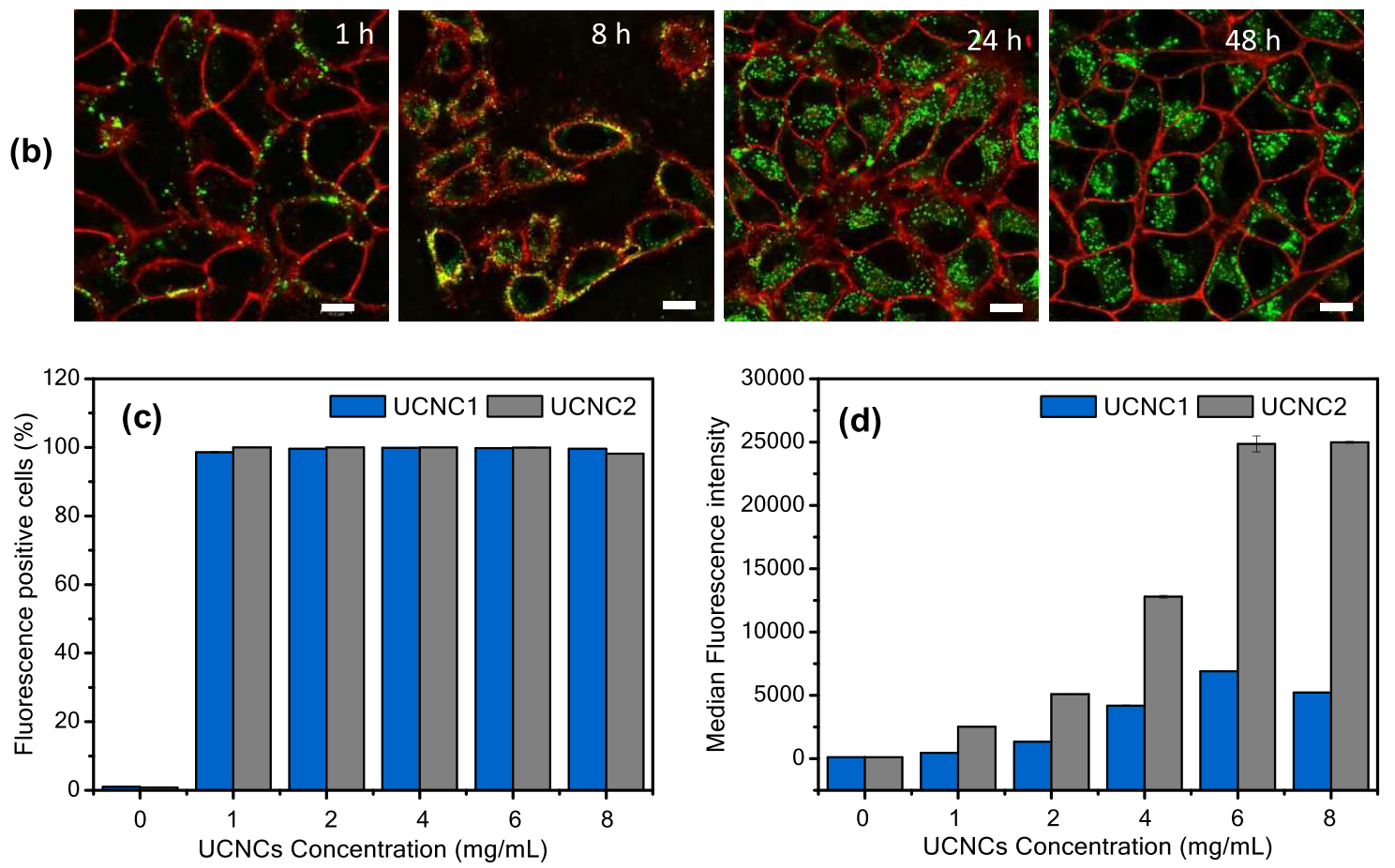

Figure 3. (a) Cell viability assay of HeLa cells after being treated with the UCNCs for $24 \mathrm{~h}$. (b) Confocal laser scanning microscopy (cLSM) images of HeLa cells incubated with UCNC2 at $6 \mathrm{mg} \cdot \mathrm{mL}^{-1}$ for various incubation times. The cell membrane was stained with CellMaskOrange and pseudocolored in red. The direct fluorescence emission from encapsulated BDMBP dye was detected and pseudocolored in green. The scale bar is $10 \mu \mathrm{m}$. Flow cytometry analysis showing (c) percentage of fluorescence-positive cells and (d) median fluorescence intensity (MFI) obtained from the direct fluorescence emission of encapsulated BDMBP dye in UCNC1 and UCNC2 incubated in HeLa cells for $24 \mathrm{~h}$.

less already dissolved in the dispersion and the rice bran oil has already partly oxidized. In addition, when we compared the luminescent spectra of UCNCM and UCNC1 under these glovebox conditions (Figure S5, SI), the RBO bearing nanocapsules showed about 7 times higher UC efficiency than the $\mathrm{HD}$ bearing ones. This enhancement is, of course, on the one hand related to the mobility of the dyes in the RBO, but on the other hand, it supports our claim that even the ppm level of oxygen has an effect on UC efficiency. Additionally, the diffusion rate of the oxygen through the PMMA shell was found to be at a remarkable level, as also observed in our previous study. ${ }^{29}$ In conclusion, our hypothesis is that the increase in the amount of dye at the UCNC core may push them to closer contact with the PMMA shell. This in turn could result in change of the dye mobility, so that they become more prone to any changes in the environment such as increased oxygen diffusion at higher temperatures. Figure S6 shows the proposed mechanism for this behavior. Although the TTA-UC process is highly unique for specific environments, the temperature dependence of the nanocapsules was clearly outlined in an aqueous environment at maximum concentration $\left(41 \mathrm{mg} \cdot \mathrm{mL}^{-1}\right)$. We then proceeded to the phase of cellular uptake and further in vitro sensing.

Cellular Uptake and Viability. Prior to the assessment of in vitro temperature sensing, the cellular uptake and viability of the established nanocapsules were examined. Here, HeLa cells were chosen for the in vitro assay to mimic a cancerous environment. First, a cytotoxicity assay was performed to determine the optimal concentration of the UCNCs for further use as a potential nanothermometer. Various concentrations of 

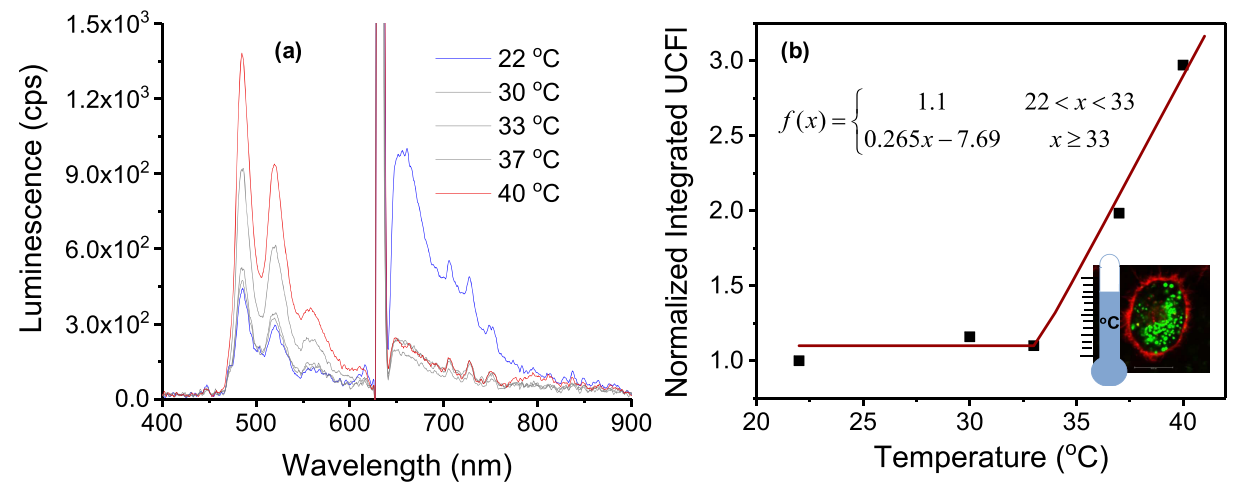

Figure 4. (a) Temperature-dependent luminescent spectra of UCNC2 nanocapsules taken up by HeLa cells, excitation at $\lambda_{\text {exc }}=633 \mathrm{~nm}, 256 \mathrm{~mW}$. $\mathrm{cm}^{-2} \mathrm{HeNe}$ laser. (b) Temperature-dependence of the normalized integral UC fluorescence (UCFl) defined from the spectra in part a (integral region is from $\lambda_{0}=460 \mathrm{~nm}$ to $\lambda_{\mathrm{f}}=620 \mathrm{~nm}$ ) for use as a potential calibration curve (Residual phosphorescence is small but almost constant). Inset, confocal image of HeLa cells with UCNCs illustrating use as a nanothermometer.

the UCNCs ranging from 0.5 to $10 \mathrm{mg} \cdot \mathrm{mL}^{-1}$ were incubated with the cells for $24 \mathrm{~h}$. After that, the cell viability was determined as shown in Figure 3a. The UCNCs decreased the cell viability in a dose-dependent manner, and their halfmaximal effective concentration $\left(\mathrm{EC}_{50}\right)$ was similar at $6.95 \mathrm{mg}$. $\mathrm{mL}^{-1}$ for UCNC1 and $6.22 \mathrm{mg} \cdot \mathrm{mL}^{-1}$ for UCNC2. These are high numbers and indicate that the established nanocapsules are decidedly biocompatible.

The next step was to study the cellular uptake of the corresponding nanocapsules to select a sufficient loading amount for an upconversion signal from the HeLa cells. To do this, flow cytometry analysis was performed by following the direct fluorescence emission of BDMBP dye as already present in UCNPs that was taken up by the cells after $24 \mathrm{~h}$. Figure $3 \mathrm{c}$ showed about $100 \%$ of fluorescence-positive cells when the concentration of the UCNPs had reached $1 \mathrm{mg} \cdot \mathrm{mL}^{-1}$. However, the median fluorescence intensity (MFI) obtained from the cells treated with UCNC2 (containing the higher amount of BDMBP dye) was higher than that of UCNC1 at the same concentration of the nanocapsules, as shown in Figure $3 \mathrm{~d}$. This stronger signal confirms the high potential of those nanocapsules to be used as a reporter in physiological temperature measurement. Moreover, the MFI value reached its maximum level at $6 \mathrm{mg} \cdot \mathrm{mL}^{-1}$ and did not increase more in the case of higher concentrations, as observed for $8 \mathrm{mg} \cdot \mathrm{mL}^{-1}$ in Figure 3d. Therefore, the maximum concentration that gave the highest fluorescence signal while still being less toxic to the cell at $6 \mathrm{mg} \cdot \mathrm{mL}^{-1}$ for both UCNC1 and UCNC2 was selected for further temperature sensing investigations in HeLa cells. Nevertheless, before proceeding to the final step, the cellular uptake of UCNC2 at $6 \mathrm{mg} \cdot \mathrm{mL}^{-1}$ in HeLa cells was further investigated by confocal laser scanning microscopy (cLSM) after different incubation times. Figure $3 \mathrm{~b}$ shows the progress of the cellular uptake process. After $1 \mathrm{~h}$ of incubation, only a small number of UCNPs surrounded the HeLa cells. After $8 \mathrm{~h}$, more nanocapsules were colocalized with the membrane and some of them were already inside the HeLa cells. After $24 \mathrm{~h}$, a high number of the nanocapsules were taken up by every cell, and this status remained stable even after $48 \mathrm{~h}$ of incubation. Thus, this not only confirmed the higher efficiency of the cellular uptake of the nanocapsules but also supported their biocompatibility with the cells.

Temperature Sensing in HeLa Cells. After the confirmation of cellular uptake and biocompatibility with the cells, we performed the in vitro TTA-UC measurements to evaluate the potential of our PMMA nanocapsules as a nanothermometer. The first investigation was to ensure sufficient upconversion efficiency at mild excitation power required to achieve the temperature-sensing response when UCNCs are inside the HeLa cells. As mentioned previously, 6 $\mathrm{mg} \cdot \mathrm{mL}^{-1}$ of the UCNC1 and UCNC2 nanocapsules were taken up by the HeLa cells. This was then followed by excitation with a $633 \mathrm{~nm}$ HeNe laser, increasing the excitation intensity stepwise from $32 \mathrm{~mW} \mathrm{~cm}^{-2}$ to $256 \mathrm{~mW} \mathrm{~cm}^{-2}$ at a fixed temperature $\left(22^{\circ} \mathrm{C}\right.$, Figure S7, see SI). At this point, we were not able to obtain a UC signal from the UCNC1 nanocapsules in HeLa cells at this range of excitation intensity. It should be noted that this is clearly related to the lower concentration of the nanocapsules; in the case of cell incubation, we were only able to use a 7 times lower nanocarrier concentration. In contrast, the higher dye-loaded nanocapsules (UCNC2) in HeLa cells were able to function well at varied light excitation intensities, as shown in Figure S7 (see SI). Again, the situation after 7 times dilution led to lower efficiencies (Figure S7) than that of the entire bulk status of the nanocapsules (Figure 2d), but the obtained UC efficiency of nanocapsules in cells was sufficient for determining the in vitro temperature response of the UCNCs (Figure 4). In addition, the residual phosphorescence signal was lower and spectrally overlapped with the autofluorescence of the cell. The cell autofluorescence was investigated by parallel experiments using control HeLa cell dishes without nanocapsules (Figure S8, see SI). Additionally, the observed optical signal with local maximum at $\lambda=660 \mathrm{~nm}$ was strongly temperature-dependent; this signal decreased strongly after increasing the sample temperature (Figure 4a).

In Figure $4 a$, we report on the temperature-dependent luminescent spectra of living HeLa cells incubated with UCNC2 nanocapsules. The temperature interval studied was deliberately limited to 22 to $40{ }^{\circ} \mathrm{C}$ in order not to impair the HeLa cell metabolism too extensively or irreversibly. In this temperature range, almost a constant intensity of the residual phosphorescence signal (at $\lambda_{\max }=800 \mathrm{~nm}$, Figure 4a) was observed. In addition, the UC fluorescence increased monotonically with increasing sample temperature. An important outcome here is that the increase of the HeLa cell temperature obviously showed a more pronounced effect on the intensity of the UC signal for $T>33^{\circ} \mathrm{C}$, than in the range of $20-33{ }^{\circ} \mathrm{C}$. This can most probably be attributed to enhanced cellular activity at higher temperatures, which in turn 
leads to increased oxygen consumption. HeLa cells utilize $\mathrm{O}_{2}$ of about $26.9 \mathrm{amol} / \mathrm{cell}^{55}$ at $37^{\circ} \mathrm{C}$. This becomes a supporting reaction to the deoxygenation of the $\mathrm{RBO}$ core when compared with the case of more highly concentrated nanocapsules in dispersion. Here, the cells act as an additional support for the in vitro TTA-UC process, and it is likely that the in vitro TTA-UC mimics the situation we have seen in UCNC1 nanocapsules (Figure 2d) in which UC fluorescence increases with temperature. This again confirms that the oxygen presence and all further physical/chemical activities together form the unique conditions as illustrated in Figure S9 (see SI). Briefly, the combination of all these situations leads to a lower oxygen concentration at a certain time and at higher temperatures, all resulting in enhanced UC fluoresence with increasing temperature. Figure $4 \mathrm{~b}$ reflects this behavior by showing that the UC signal increased more than three times at temperatures close to $40{ }^{\circ} \mathrm{C}$ compared to a temperature at 22 ${ }^{\circ} \mathrm{C}$. This result compares well with the data obtained for UCNC1 nanocapsules (Figure 2c), as enhancement was also in this range. It should be noted that the total dye amount hosted by the diluted UCNC2 nanocapsules $\left(6 \mathrm{mg} \cdot \mathrm{mL}^{-1}\right)$ inside the HeLa cells (Figure 4) were similar to the dye amounts in the raw UCNC1 nanocapsules (Figure 2c). Given this, it is not surprising that TTA-UC processing with UCNC1 nanocapsules more closely mimic the in vitro TTA-UC process inside the HeLa cells. Thus, a minimally invasive way of temperature sensing in HeLa cells was shown for the first time by using PMMA based upconversion nanocapsules.

\section{CONCLUSIONS}

In this study, we have demonstrated how polymeric upconversion nanocapsules that utilize triplet-triplet annihilation upconversion-based temperature responsivity can be used as potential minimally invasive nanothermometers in living cells. The fabricated nanocapsules consisted of a poly(methyl methacrylate) shell and a rice bran oil core hosting the upconversion sensitizer and emitter dye molecules. Different amounts of dye encapsulation were shown to perform triplet-triplet annihilation upconversion in an aqueous medium and can be applied in further uses of temperature probing within a biological environment. The upconversion nanocapsules can function within the presence of different oxygen levels, including the fully air-saturated condition that supports the antioxidant capacity with the aid of unsaturated fatty acids in the rice bran oil core. In addition, the good cellular uptake and biocompatibility, as well as further temperature sensing through in vitro triplet-triplet annihilation upconversion process with a mild excitation intensity by red light, open up new opportunities of designing nanothermometers to gain more detailed information about cellular activities. This has the potential for further advances in medical applications, especially the early diagnosis and treatment of diseases like cancer.

\section{ASSOCIATED CONTENT}

\section{s) Supporting Information}

The Supporting Information is available free of charge at https://pubs.acs.org/doi/10.1021/acs.biomac.0c00377.

Additional characterization and experimental data (PDF)

\section{AUTHOR INFORMATION}

\section{Corresponding Author}

Katharina Landfester - Max Planck Institute for Polymer

Research, 55128 Mainz, Germany; ㅇo이.org/0000-00019591-4638; Email: landfester@mpip-mainz.mpg.de

\section{Authors}

Banu Iyisan - Max Planck Institute for Polymer Research, 55128 Mainz, Germany; 이이.org/0000-0003-3989-119X

Raweewan Thiramanas - Max Planck Institute for Polymer Research, 55128 Mainz, Germany; 이이.org/0000-00026881-6247

Nadzeya Nazarova - Max Planck Institute for Polymer Research, 55128 Mainz, Germany

Yuri Avlasevich - Max Planck Institute for Polymer Research, 55128 Mainz, Germany

Volker Mailänder - Max Planck Institute for Polymer Research, 55128 Mainz, Germany; Dermatology Clinic, University Medical Center of the Johannes Gutenberg-University Mainz, 55131 Mainz, Germany; 이이.org/0000-0001-6583-8136

Stanislav Baluschev - Max Planck Institute for Polymer Research, 55128 Mainz, Germany; Optics and Spectroscopy Department, Faculty of Physics, Sofia University, 1164 Sofia, Bulgaria

Complete contact information is available at:

https://pubs.acs.org/10.1021/acs.biomac.0c00377

\section{Notes}

The authors declare no competing financial interest.

\section{ACKNOWLEDGMENTS}

This work was performed under the European Horizon 2020 research and innovation program, Grant Agreement No 732794-project HYPOSENS. Raweewan Thiramanas was supported by the National Nanotechnology Center, Thailand, and received a Royal Thai government scholarship.

\section{REFERENCES}

(1) Hildebrandt, B.; Wust, P.; Ahlers, O.; Dieing, A.; Sreenivasa, G.; Kerner, T.; Felix, R.; Riess, H. The cellular and molecular basis of hyperthermia. Crit. Rev. in Oncol. Hematol. 2002, 43, 33-56.

(2) Lowell, B. B.; Spiegelman, B. M. Towards a molecular understanding of adaptive thermogenesis. Nature 2000, 404, 652660.

(3) Rao, P. N.; Engelberg, J. HeLa Cells: Effects of Temperature on the Life Cycle. Science 1965, 148, 1092-1094.

(4) Monti, M.; Brandt, L.; Ikomi-Kumm, J.; Olsson, H. Microcalorimetric investigation of cell metabolism in tumour cells from patients with non-Hodgkin lymphoma (NHL). Scand. J. Haematol. 1986, 36, 353-357.

(5) Karnebogen, M.; Singer, D.; Kallerhoff, M.; Ringert, R. H. Microcalorimetric investigations on isolated tumorous and nontumorous tissue samples. Thermochim. Acta 1993, 229, 147-155.

(6) Cui, J.; van Koeverden, M. P.; Müllner, M.; Kempe, K.; Caruso, F. Emerging methods for the fabrication of polymer capsules. $A d v$. Colloid Interface Sci. 2014, 207, 14-31.

(7) Musyanovych, A.; Landfester, K. Polymer Micro- and Nanocapsules as Biological Carriers with Multifunctional Properties. Macromol. Biosci. 2014, 14, 458-477.

(8) Iyisan, B.; Landfester, K. Modular Approach for the Design of Smart Polymeric Nanocapsules. Macromol. Rapid Commun. 2019, 40, 1800577.

(9) Schmaljohann, D. Thermo- and $\mathrm{pH}$-responsive polymers in drug delivery. Adv. Drug Delivery Rev. 2006, 58, 1655-1670. 
(10) Jaque, D.; Rosal, B. d.; Rodríguez, E. M.; Maestro, L. M.; HaroGonzález, P.; Solé, J. G. Fluorescent nanothermometers for intracellular thermal sensing. Nanomedicine 2014, 9, 1047-1062.

(11) Jaque, D.; Vetrone, F. Luminescence nanothermometry. Nanoscale 2012, 4, 4301-4326.

(12) Qin, T.; Liu, B.; Zhu, K.; Luo, Z.; Huang, Y.; Pan, C.; Wang, L. Organic fluorescent thermometers: Highlights from 2013 to 2017. TrAC, Trends Anal. Chem. 2018, 102, 259-271.

(13) Uchiyama, S.; Gota, C.; Tsuji, T.; Inada, N. Intracellular temperature measurements with fluorescent polymeric thermometers. Chem. Commun. 2017, 53, 10976-10992.

(14) Baffou, G.; Rigneault, H.; Marguet, D.; Jullien, L. A critique of methods for temperature imaging in single cells. Nat. Methods 2014, 11, 899-901.

(15) Frangioni, J. V. In vivo near-infrared fluorescence imaging. Curr. Opin. Chem. Biol. 2003, 7, 626-634.

(16) Stolik, S.; Delgado, J. A.; Pérez, A.; Anasagasti, L. Measurement of the penetration depths of red and near infrared light in human "ex vivo" tissues. J. Photochem. Photobiol., B 2000, 57, 90-93.

(17) Zhou, J.; Liu, Q.; Feng, W.; Sun, Y.; Li, F. Upconversion Luminescent Materials: Advances and Applications. Chem. Rev. 2015, $115,395-465$.

(18) Denk, W.; Strickler, J.; Webb, W. Two-photon laser scanning fluorescence microscopy. Science 1990, 248, 73-76.

(19) Clark, H. A.; Campagnola, P. J.; Wuskell, J. P.; Lewis, A.; Loew, L. M. Second Harmonic Generation Properties of Fluorescent Polymer-Encapsulated Gold Nanoparticles. J. Am. Chem. Soc. 2000, 122, 10234-10235.

(20) Chen, G.; Qiu, H.; Prasad, P. N.; Chen, X. Upconversion Nanoparticles: Design, Nanochemistry, and Applications in Theranostics. Chem. Rev. 2014, 114, 5161-5214.

(21) Simon, Y. C.; Weder, C. Low-power photon upconversion through triplet-triplet annihilation in polymers. J. Mater. Chem. 2012, 22, 20817-20830.

(22) Gray, V.; Moth-Poulsen, K.; Albinsson, B.; Abrahamsson, M. Towards efficient solid-state triplet-triplet annihilation based photon upconversion: Supramolecular, macromolecular and self-assembled systems. Coord. Chem. Rev. 2018, 362, 54-71.

(23) Murakami, Y.; Das, S. K.; Himuro, Y.; Maeda, S. Tripletsensitized photon upconversion in deep eutectic solvents. Phys. Chem. Chem. Phys. 2017, 19, 30603-30615.

(24) Roussakis, E.; Li, Z.; Nowell, N. H.; Nichols, A. J.; Evans, C. L. Bright, "Clickable" Porphyrins for the Visualization of Oxygenation under Ambient Light. Angew. Chem., Int. Ed. 2015, 54, 14728-14731.

(25) Turshatov, A.; Busko, D.; Baluschev, S.; Miteva, T.; Landfester, K. Micellar carrier for triplet-triplet annihilation-assisted photon energy upconversion in a water environment. New J. Phys. 2011, 13, 083035 .

(26) Monguzzi, A.; Frigoli, M.; Larpent, C.; Tubino, R.; Meinardi, F. Low-Power-Photon Up-Conversion in Dual-Dye-Loaded Polymer Nanoparticles. Adv. Funct. Mater. 2012, 22, 139-143.

(27) Thévenaz, D. C.; Monguzzi, A.; Vanhecke, D.; Vadrucci, R.; Meinardi, F.; Simon, Y. C.; Weder, C. Thermoresponsive low-power light upconverting polymer nanoparticles. Mater. Horiz. 2016, 3, 602-607.

(28) Wohnhaas, C.; Turshatov, A.; Mailänder, V.; Lorenz, S.; Baluschev, S.; Miteva, T.; Landfester, K. Annihilation Upconversion in Cells by Embedding the Dye System in Polymeric Nanocapsules. Macromol. Biosci. 2011, 11, 772-778.

(29) Wohnhaas, C.; Mailänder, V.; Dröge, M.; Filatov, M. A.; Busko, D.; Avlasevich, Y.; Baluschev, S.; Miteva, T.; Landfester, K.; Turshatov, A. Triplet-Triplet Annihilation Upconversion Based Nanocapsules for Bioimaging Under Excitation by Red and DeepRed Light. Macromol. Biosci. 2013, 13, 1422-1430.

(30) Kwon, O. S.; Song, H. S.; Conde, J.; Kim, H.-i.; Artzi, N.; Kim, J.-H. Dual-Color Emissive Upconversion Nanocapsules for Differential Cancer Bioimaging In Vivo. ACS Nano 2016, 10, 1512-1521.

(31) Liu, Q.; Yin, B.; Yang, T.; Yang, Y.; Shen, Z.; Yao, P.; Li, F. A General Strategy for Biocompatible, High-Effective Upconversion
Nanocapsules Based on Triplet-Triplet Annihilation. J. Am. Chem. Soc. 2013, 135, 5029-5037.

(32) Baluschev, S.; Katta, K.; Avlasevich, Y.; Landfester, K. Annihilation upconversion in nanoconfinement: solving the oxygen quenching problem. Mater. Horiz. 2016, 3, 478-486.

(33) Kim, J.-H.; Kim, J.-H. Encapsulated Triplet-Triplet Annihilation-Based Upconversion in the Aqueous Phase for Sub-Band-Gap Semiconductor Photocatalysis. J. Am. Chem. Soc. 2012, 134, 1747817481.

(34) Ye, C.; Wang, B.; Hao, R.; Wang, X.; Ding, P.; Tao, X.; Chen, Z.; Liang, Z.; Zhou, Y. Oil-in-water microemulsion: an effective medium for triplet-triplet annihilated upconversion with efficient triplet acceptors. J. Mater. Chem. C 2014, 2, 8507-8514.

(35) Marsico, F.; Turshatov, A.; Peköz, R.; Avlasevich, Y.; Wagner, M.; Weber, K.; Donadio, D.; Landfester, K.; Baluschev, S.; Wurm, F. R. Hyperbranched Unsaturated Polyphosphates as a Protective Matrix for Long-Term Photon Upconversion in Air. J. Am. Chem. Soc. 2014, 136, 11057-11064.

(36) Bharmoria, P.; Hisamitsu, S.; Nagatomi, H.; Ogawa, T.; Morikawa, M.-a.; Yanai, N.; Kimizuka, N. Simple and Versatile Platform for Air-Tolerant Photon Upconverting Hydrogels by Biopolymer-Surfactant-Chromophore Co-assembly. J. Am. Chem. Soc. 2018, 140, 10848-10855.

(37) Svagan, A. J.; Busko, D.; Avlasevich, Y.; Glasser, G.; Baluschev, S.; Landfester, K. Photon Energy Upconverting Nanopaper: A Bioinspired Oxygen Protection Strategy. ACS Nano 2014, 8, 81988207.

(38) Xu, M.; Zou, X.; Su, Q.; Yuan, W.; Cao, C.; Wang, Q.; Zhu, X.; Feng, W.; Li, F. Ratiometric nanothermometer in vivo based on triplet sensitized upconversion. Nat. Commun. 2018, 9, 2698.

(39) Vetrone, F.; Naccache, R.; Zamarrón, A.; Juarranz de la Fuente, A.; Sanz-Rodríguez, F.; Martinez Maestro, L.; Martín Rodriguez, E.; Jaque, D.; García Solé, J.; Capobianco, J. A. Temperature Sensing Using Fluorescent Nanothermometers. ACS Nano 2010, 4, 32543258.

(40) Sedlmeier, A.; Achatz, D. E.; Fischer, L. H.; Gorris, H. H.; Wolfbeis, O. S. Photon upconverting nanoparticles for luminescent sensing of temperature. Nanoscale 2012, 4, 7090-7096.

(41) Fischer, L. H.; Harms, G. S.; Wolfbeis, O. S. Upconverting Nanoparticles for Nanoscale Thermometry. Angew. Chem., Int. Ed. 2011, 50, 4546-4551.

(42) Tian, B.; Wang, Q.; Su, Q.; Feng, W.; Li, F. In vivo biodistribution and toxicity assessment of triplet-triplet annihilationbased upconversion nanocapsules. Biomaterials 2017, 112, 10-19.

(43) Wohnhaas, C.; Friedemann, K.; Busko, D.; Landfester, K.; Baluschev, S.; Crespy, D.; Turshatov, A. All Organic Nanofibers As Ultralight Versatile Support for Triplet-Triplet Annihilation Upconversion. ACS Macro Lett. 2013, 2, 446-450.

(44) Bettencourt, A.; Almeida, A. J. Poly(methyl methacrylate) particulate carriers in drug delivery. J. Microencapsulation 2012, 29, $353-367$.

(45) Filatov, M. A.; Baluschev, S.; Ilieva, I. Z.; Enkelmann, V.; Miteva, T.; Landfester, K.; Aleshchenkov, S. E.; Cheprakov, A. V. Tetraaryltetraanthra[2,3] porphyrins: Synthesis, Structure, and Optical Properties. J. Org. Chem. 2012, 77, 11119-11131.

(46) Cheprakov, A. V.; Filatov, M. A. The dihydroisoindole approach to linearly annelated $\pi$-extended porphyrins. J. Porphyrins Phthalocyanines 2009, 13, 291-303.

(47) Ju, Y.-H.; Vali, S. R. Rice bran oil as a potential resource for biodiesel: a review. J. Sci. Ind. Res. 2005, 64, 866-882.

(48) Keivanidis, P. E.; Baluschev, S.; Lieser, G.; Wegner, G. Inherent Photon Energy Recycling Effects in the Up-Converted Delayed Luminescence Dynamics of Poly(fluorene)-PtIloctaethyl Porphyrin Blends. ChemPhysChem 2009, 10, 2316-2326.

(49) Nazarova, N. V.; Avlasevich, Y.; Landfester, K.; Baluschev, S. Stimuli-responsive protection of optically excited triplet ensembles against deactivation by molecular oxygen. Dalton Trans. 2018, 47, $8605-8610$ 
(50) Stich, M. I. J.; Fischer, L. H.; Wolfbeis, O. S. Multiple fluorescent chemical sensing and imaging. Chem. Soc. Rev. 2010, 39, $3102-3114$.

(51) Filatov, M. A.; Heinrich, E.; Busko, B.; Ilieva, I. Z.; Landfester, K.; Baluschev, S. Reversible oxygen addition on a triplet sensitizer molecule: protection from excited state depopulation. Phys. Chem. Chem. Phys. 2015, 17, 6501-6510.

(52) Pope, M.; Swenberg, C. E. Electronic processes in organic crystals and polymers; Oxford University Press: New York, 1999, Vol. 2.

(53) Duan, P.; Yanai, N.; Nagatomi, H.; Kimizuka, N. Photon Upconversion in Supramolecular Gel Matrixes: Spontaneous Accumulation of Light-Harvesting Donor-Acceptor Arrays in Nanofibers and Acquired Air Stability. J. Am. Chem. Soc. 2015, 137, 1887-1894. (54) Askes, S. H. C.; Brodie, P.; Bruylants, G.; Bonnet, S. Temperature Dependence of Triplet-Triplet Annihilation Upconversion in Phospholipid Membranes. J. Phys. Chem. B 2017, 121, $780-786$.

(55) Wagner, B. A.; Venkataraman, S.; Buettner, G. R. The rate of oxygen utilization by cells. Free Radical Biol. Med. 2011, 51, 700-712. 